\title{
Endoscopic submucosal dissection for early gastric cancer in very elderly patients age $\mathbf{8 5}$ or older
}

\section{(웅 $\odot$}

\author{
Authors \\ Ko Watanabe ${ }^{1,2}$, Takuto Hikichi ${ }^{1}$, Jun Nakamura ${ }^{1,2}$, Tadayuki \\ Takagi $^{2}$, Rei Suzuki², Mitsuru Sugimoto², Yuichi Waragai², Hitomi \\ Kikuchi $^{1,2}$, Naoki Konno ${ }^{1,2}$, Hiroyuki Asama², Mika Takasumi², \\ Katsutoshi Obara ${ }^{3}$, Hiromasa Ohira ${ }^{2}$ \\ Institutions \\ 1 Department of Endoscopy, Fukushima Medical University \\ Hospital, Fukushima, Japan \\ 2 Department of Gastroenterology, Fukushima Medical University \\ School of Medicine, Fukushima, Japan \\ 3 Department of Advanced Gastrointestinal Endoscopy, \\ Fukushima Medical University, Fukushima, Japan
}

submitted 2.2.2016

accepted after revision $\quad 24.10 .2016$

Bibliography

DOI http://dx.doi.org/10.1055/s-0042-122960 |

Endoscopy International Open 2017; 05: E17-E24

(c) Georg Thieme Verlag KG Stuttgart · New York

ISSN 2364-3722

Corresponding author

Takuto Hikichi, MD, PhD, Director and Associate Professor,

Department of Endoscopy, Fukushima Medical University Hospital,

1 Hikarigaoka, Fukushima, Japan, 960-1295

Phone: +81-24-547-1583

Fax: +81-24-547-1586

takuto@fmu.ac.jp

\begin{abstract}
Background and study aims The safety and efficacy of endoscopic submucosal dissection (ESD) for early gastric cancer (EGC) in very elderly patients remains unclear. The aim of this study was to evaluate the safety and efficacy of ESD for EGC in patients age 85 years and older.

Patients and methods Patients who underwent ESD for EGC between September 2003 and April 2015 were divided into 3 groups: the very elderly ( $\geq 85$ years; 43 patients), the elderly (65-84 years; 511 patients), and the non-elderly ( $\leq 64$ years; 161 patients). Adverse events (AEs) were used as the primary endpoint to assess the safety of ESD, and the ESD treatment outcomes (i. e., en bloc resection rate, complete en bloc resection rate, and curative resection rate) and the overall survival rate after ESD were the secondary endpoints. These parameters were retrospectively evaluated in the 3 groups.

Results There were no significant differences in AEs (non-elderly, elderly, and very elderly: $7.3,9.5$, and $12.5 \%$, respectively, $P=$ 0.491 ) or in the en bloc resection and complete en bloc resection rates among the three groups. However, there was a significant difference in the curative resection rates (non-elderly, elderly, and very elderly: $91.5,84.1$, and $77.1 \%$, respectively, $P=0.014$ ). Regarding overall survival, there was a significant difference among the three groups (1-, 5-, and 10-year overall survival rates: non-elderly: 98.6, 90.2, and $74.7 \%$; elderly: $97.2,86.2$, and $61.9 \%$; and very elderly: $92.7,66.8$, and $34.4 \%$, respectively, $P=0.001$ ). Moreover, the overall survival rate in the very elderly patients with cardiovascular disease was significantly lower than that in the very elderly patients without cardiovascular disease $(P<0.001)$.

Conclusions ESD is an acceptable treatment for EGC in patients 85 years of age or older in terms of safety. However, the overall survival after ESD in the very elderly patients with cardiovascular disease was short.
\end{abstract}

\section{Introduction}

The elderly population has been growing dramatically in Japan. According to the 2015 World Health Report by the World Health Organization (WHO), the average life expectancy of Japanese women is 87 years and that of men is 80 years (World Health Organization, World health statistics 2015 (March 13, 2015), http://www.who.int/gho/publication/world_health_statistics/2015/en/). In Japan's increasingly aging society, a growing number of esophagogastroduodenoscopy (EGD) procedures have been performed in elderly patients. Consequently, EGD more frequently reveals early gastric cancer (EGC) in elderly patients. Moreover, we occasionally encounter patients 85 years of age or older, who are defined as very elderly patients by geriatric researchers [1], with EGC, and we are increasingly faced with the problem of treating these patients.
Endoscopic submucosal dissection (ESD) enables reliable en bloc resection via a minimally invasive treatment and is now standard treatment for EGC, particularly for differentiated mucosal cancers that have a low risk of lymph node metastasis [2, 3]. The efficacy of gastric ESD for elderly patients has been reported [4-11]. However, several authors have reported that the rates of pneumonia and bleeding associated with ESD in elderly patients are significantly higher than the rates in non-elderly patients $[5,8,9,11]$. Therefore, we are concerned about the adverse events (AEs) of ESD in very elderly patients because they often have poor overall health status [12]. In adddition, the long-term outcomes of ESD in very elderly patients are not well known. Currently, only a single report concerning clinical outcomes of ESD for EGC in very elderly patients has been published [13]. However, no previous reports have discussed outcomes of ESD in very elderly patients compared to those in el- 
derly or non-elderly patients. Therefore, we conducted this study to evaluate the safety and efficacy of ESD for EGC in very elderly patients.

\section{Patients and methods}

\section{Patients}

A total of 877 consecutive EGCs (excluding patients with residual stomach and gastric tubes) in 715 patients were treated by ESD at the Fukushima Medical University Hospital between September 2003 and April 2015. The patients were divided into 3 groups based on age: very elderly ( $\geq 85$ years; 48 lesions in 43 patients), elderly (65-84 years; 652 lesions in 511 patients), and non-elderly ( $\leq 64$ years; 177 lesions in 161 patients). People age 65 years or older were considered elderly, and elderly and non-elderly patients were defined based on WHO definitions (World Health Organization, Health statistics and information systems, http://www.who.int/healthinfo/survey/ageingdefnolder/en/). Furthermore, we defined very elderly as patients who were age 85 years or older, in accordance with geriatric researchers [1].

Indications for ESD in EGC included the following based on endoscopic diagnosis with mucosal biopsy: 1) differentiated intramucosal cancer without ulceration; 2) differentiated intramucosal cancer of $3 \mathrm{~cm}$ or less with ulceration; and 3) undifferentiated intramucosal cancer of $2 \mathrm{~cm}$ or less without ulceration. Other inclusion criteria were that patients had a performance status $(P S) \leq 2$, were eligible for ESD or emergency surgery if they were without severe comorbidities, had no other advanced cancer as a prognostic factor, and provided consent to undergo ESD. Patients with other advanced cancers as prognostic factors first underwent treatments for those conditions. In these patients, ESD for EGC was only performed after recovery from treatment for other cancers. Patients were defined as having comorbidities if they had been diagnosed with cardiovascular disease by echocardiography or electrocardiograph, respiratory disease based on a chest computed tomography scan or respiratory function test, or if they were currently being treated. All patients provided written informed consent before the ESD procedure, and this study was conducted with the approval of the Ethics Committee of Fukushima Medical University (approval No. 2516).

\section{ESD procedure}

ESD was performed with a Dual Knife (KD-650L; Olympus Medical Systems Corp., Tokyo, Japan), a Flex Knife (KD-630L; Olympus Medical Systems Corp., Tokyo, Japan), an IT Knife (KD-610L; Olympus Medical Systems Corp., Tokyo, Japan) or an IT Knife 2 (KD-611L; Olympus Medical Systems Corp., Tokyo, Japan). A 1:1 solution of $0.4 \%$ sodium hyaluronate (MucoUp; Johnson \& Johnson K.K., Tokyo, Japan) and glycerol (Chugai Pharmaceutical Co. Ltd., Tokyo, Japan) was injected into the submucosa using a 25$\mathrm{G}$ injection needle (ImpactFlow; TOP Corp., Tokyo, Japan). Hemostatic forceps (Coagrasper; FD410LR; Olympus Medical Systems Corp., Tokyo, Japan) were used for the prophylactic coagulation of blood vessels and hemostasis for intraoperative bleeding. A VIO300 D or ICC200 (ERBE Elektromedizin $\mathrm{GmbH}$,
Tübingen, Germany) was used as the high-frequency generator. All patients were sedated with a combination of midazolam (before February 2014) or propofol (after February 2014) and pentazocine. During all ESD procedures, patients' vital signs were monitored using a percutaneous oxygen saturation monitor and an automatic blood pressure monitor, and oxygen was administered through a nasal cannula. All ESDs were performed by expert physicians who were board-certified gastroenterological endoscopists of the Japan Gastroenterological Endoscopy Society or by less-experienced physicians (i.e., those who had performed fewer than 50 ESD procedures) under the supervision of the expert physicians.

\section{Outcomes}

The primary endpoint was AEs following ESD, and this endpoint was compared among the 3 groups (i.e., the non-elderly, elderly, and very elderly). Secondary endpoints were treatment outcomes of ESD (i.e., the en bloc resection, complete en bloc resection, and curative resection rates) and overall long-term survival rate after ESD. These endpoints were also compared among the 3 groups.

Tumor locations were classified as upper $(U)$, middle $(M)$, or lower (L) stomach according to the Japanese classification of gastric carcinoma established by the Japanese Gastric Cancer Association [14]. Resected specimens were sliced into 2-mm sections. Tumor size, histologic type, depth of invasion, ulcer findings, lymphovascular invasion, and horizontal and vertical resection margins were macroscopically assessed. Histologic type was classified into differentiated type (well and moderately differentiated adenocarcinomas and papillary adenocarcinomas) and undifferentiated type (poorly differentiated adenocarcinomas, signet ring cell carcinomas, and mucinous adenocarcinomas). When a tumor exhibited a mixture of differentiated and undifferentiated types, the histologic type was classified according to major tumor components. Complete en bloc resection was defined as resection in a single piece that included the tumor-free margin. Specimens that satisfied the following criteria were considered to represent en bloc curative resections: 1) differentiated intramucosal cancer without ulceration and with no lymphovascular invasion; 2) differentiated intramucosal cancer of $3 \mathrm{~cm}$ or less with ulceration and with no lymphovascular invasion; 3) differentiated minimally invasive submucosal (invasion depth $<500 \mu \mathrm{m}$ from the muscularis mucosa: $\mathrm{SM} 1$ ) cancer of $3 \mathrm{~cm}$ or less without ulceration and with no lymphovascular invasion; and 4) undifferentiated intramucosal cancer of $2 \mathrm{~cm}$ or less without ulceration and with no lymphovascular invasion.

Regarding AEs, perforation was diagnosed when the omentum or the abdominal cavity was endoscopically visible or when free air was recognized on a computed tomography (CT) image. CT was performed only when a perforation might have occurred endoscopically during the ESD. Postoperative bleeding was defined as the occurrence of hematemesis or tarry stool with endoscopic confirmation of bleeding or exposed vessels. Aspiration pneumonia was diagnosed on radiography with a fever of $38^{\circ} \mathrm{C}$ or higher. Stenosis was defined as the inability to 
- Table 1 Patient characteristics.

\begin{tabular}{|c|c|c|c|c|}
\hline & $\begin{array}{l}\text { Non-elderly } \\
\text { ( } \leq 64 \text { years) }\end{array}$ & $\begin{array}{l}\text { Elderly } \\
\text { (65-84 years) }\end{array}$ & $\begin{array}{l}\text { Very elderly } \\
\text { ( } \geq 85 \text { years) }\end{array}$ & $P$ value \\
\hline Patients, $\mathrm{n}$ & 161 & 511 & 43 & \\
\hline Median age, years (range) & $60(40-64)$ & $75(65-84)$ & $86(85-90)$ & $<0.001$ \\
\hline Gender (Male/Female) & $134 / 27$ & $352 / 159$ & $27 / 16$ & $<0.001$ \\
\hline Performance status $(0 / 1 / 2)$ & $152 / 8 / 1$ & $383 / 112 / 16$ & $20 / 23 / 0$ & $<0.001$ \\
\hline \multicolumn{5}{|l|}{ Comorbidities, n (\%) } \\
\hline Cardiovascular disease & $10(6.2 \%)$ & $75(13.3 \%)$ & $9(21.0 \%)$ & 0.006 \\
\hline Respiratory disease & $6(3.7 \%)$ & $29(5.7 \%)$ & $2(4.7 \%)$ & 0.615 \\
\hline Hypertension & $58(38.0 \%)$ & $247(48.3 \%)$ & $21(48.8 \%)$ & 0.022 \\
\hline Diabetes mellitus & $21(13.4 \%)$ & $80(15.7 \%)$ & $6(14.0 \%)$ & 0.904 \\
\hline Cerebral vessel disease & $6(3.7 \%)$ & $53(10.1 \%)$ & $6(14.0 \%)$ & 0.020 \\
\hline Liver cirrhosis & $5(3.1 \%)$ & $17(3.3 \%)$ & $0(0 \%)$ & 0.489 \\
\hline Renal failure & $2(1.2 \%)$ & $6(1.2 \%)$ & $0(0 \%)$ & 0.770 \\
\hline Use of antithrombotic agents, $\mathrm{n}(\%)$ & $17(11.0 \%)$ & $123(24.1 \%)$ & $13(30.2 \%)$ & 0.005 \\
\hline
\end{tabular}

pass the gastroscope, which had a diameter of $9.2 \mathrm{~mm}$ (GIFQ260; Olympus Medical Systems Corp., Tokyo, Japan).

Follow-up endoscopic examinations were conducted 2 months after ESD and every 6 or 12 months thereafter. CT was also performed every 6 months on patients with non-curative resections who were followed up without additional surgery. Follow-up information was collected from medical records. If patients were followed up outside of our institution, we conducted a questionnaire survey with their primary care physicians. If patients did not make any hospital visits during the follow-up period, we contacted their home to determine whether they were alive.

\section{Statistical analysis}

Values are reported as the medians with ranges. Significant differences in patient characteristics and ESD outcomes were evaluated using the Kruskal-Wallis test or $x^{2}$-test. Overall patient survival rates were estimated using the Kaplan-Meier method. Survival rate comparisons were performed using the log-rank test. Differences were considered statistically significant at $P<0.05$. These analyses were performed using SPSS software (version 21 for Windows; IBM Corp, Armonk, NY, USA).

\section{Results}

\section{Patient and lesion characteristics}

Patient characteristics are summarized in $>$ Table 1 . There were significant differences in gender, performance status, proportion of patients with cardiovascular diseases (i.e., ischemic heart disease, valvular heart disease, chronic heart failure, and atrial fibrillation), presence of hypertension, presence of cerebral vessel disease, and use of antithrombotic agents among the three groups $(P<0.001, P<0.001, P=0.006, P=0.022, P=$ 0.020 , and $P=0.005$, respectively). In the very elderly group, 4 patients taking warfarin underwent heparin bridging therapy.

Lesion characteristics are summarized in > Table 2 . There were significant differences among the 3 groups in terms of resected specimen and tumor diameters $(P=0.030$ and $P=0.013$, respectively). However, there were no significant differences among the 3 groups regarding tumor location, histologic type, or depth of invasion.

\section{Treatment outcomes and adverse events}

Treatment outcomes and rates of AEs are summarized in $>$ Table 3. There were no significant differences in procedure time, en bloc resection rate, or complete en bloc resection rate among the 3 groups. However, there were significant differences in curative resection rate among the 3 groups $(P=0.014)$. The non-curative resection cases in the very elderly group are summarized in $>$ Table 4.

In terms of AEs, there were no significant differences with respect to rates of perforation, postoperative bleeding, aspiration pneumonia, or stricture among the three groups ( $\triangleright$ Table 3). None of the patients experienced severe adverse AEs related to sedation during or after ESD. Of all the patients, 2 experienced serious AEs and required emergency surgeries. One very elderly patient underwent an emergency laparoscopic surgery due to peritonitis that resulted from an intraoperative perforation. This patient was discharged from the hospital 12 days after surgery. Another patient in the elderly group underwent an emergency surgery due to peritonitis that resulted from a delayed perforation. This patient developed a cerebral infarction after surgery and required long-term hospitalization.

In the very elderly group, 3 patients with AEs (1 perforation and 2 pneumonias), excluding the patients who underwent he- 
- Table 2 Lesion characteristics.

\begin{tabular}{|c|c|c|c|c|}
\hline & $\begin{array}{l}\text { Non-elderly } \\
\text { ( } \leq 64 \text { years) }\end{array}$ & $\begin{array}{l}\text { Elderly } \\
\text { (65-84 years) }\end{array}$ & $\begin{array}{l}\text { Very elderly } \\
\text { ( } \geq 85 \text { years) }\end{array}$ & $P$ value \\
\hline Lesions, $\mathrm{n}$ & 177 & 652 & 48 & \\
\hline \multicolumn{4}{|l|}{ Location, n (\%) } & 0.532 \\
\hline Upper & $37(20.9 \%)$ & $122(18.7 \%)$ & $13(27.1 \%)$ & \\
\hline Middle & $73(41.2 \%)$ & $272(41.7 \%)$ & $15(31.2 \%)$ & \\
\hline Lower & $67(37.9 \%)$ & $258(39.6 \%)$ & $20(41.7 \%)$ & \\
\hline Median resected specimen diameter, mm (range) & $35(17-95)$ & $38(15-113)$ & $42(24-75)$ & 0.030 \\
\hline Median tumor diameter, mm (range) & $13(3-55)$ & $15(2-80)$ & $17(5-67)$ & 0.013 \\
\hline \multicolumn{4}{|l|}{ Histological type, n } & 0.648 \\
\hline Differentiated & 170 & 634 & 46 & \\
\hline Undifferentiated & 7 & 18 & 2 & \\
\hline \multicolumn{4}{|l|}{ Depth of invasion, $\mathrm{n}$} & 0.188 \\
\hline M & 164 & 564 & 40 & \\
\hline SM1 & 7 & 43 & 5 & \\
\hline SM2 & 6 & 45 & 3 & \\
\hline Lymphatic invasion positive, $\mathrm{n}(\%)$ & $4(2.3)$ & $44(6.7)$ & $3(6.3)$ & 0.076 \\
\hline $\begin{array}{l}\text { Vascular invasion } \\
\text { positive, } \mathrm{n}(\%)\end{array}$ & $4(2.3)$ & $44(6.7)$ & $2(4.2)$ & 0.077 \\
\hline $\begin{array}{l}\text { Location: } \mathrm{U} \text {, upper stomach; } \mathrm{M} \text {, middle stomach; L, lowe } \\
\text { Depth of invasion: } \mathrm{M} \text {, mucosal cancer; } \mathrm{SM} 1 \text {, minimally in } \\
\text { cancer, invasion depth } \geq 500 \mu \mathrm{M} \text { from the muscularis mu }\end{array}$ & $\begin{array}{l}\text { omach. } \\
\text { ive submucosal cancer, } \\
\text { a. }\end{array}$ & n depth $<500 \mu \mathrm{M}$ from th & Iscularis mucosa; SM2, & e submucosal \\
\hline & $\begin{array}{l}\text { Non-elderly } \\
\text { ( } \leq 64 \text { years) }\end{array}$ & $\begin{array}{l}\text { Elderly } \\
\text { (65-84 years) }\end{array}$ & $\begin{array}{l}\text { Very elderly } \\
\text { ( } \geq 85 \text { years) }\end{array}$ & $P$ value \\
\hline Lesions, $\mathrm{n}$ & 177 & 652 & 48 & \\
\hline Median procedure time, min (range) & $79.0(20-480)$ & $75.5(10-411)$ & $81.5(24-320)$ & 0.759 \\
\hline En bloc resection rate, \% & 97.7 & 97.4 & 97.9 & 0.948 \\
\hline Complete en bloc resection rate, \% & 96.0 & 92.9 & 93.6 & 0.317 \\
\hline Curative resection rate, $\%$ & 91.5 & 84.1 & 77.1 & 0.014 \\
\hline Adverse events, n (\%) & $13(7.3)$ & $62(9.5)$ & $6(12.5)$ & 0.491 \\
\hline Perforation & $2(1.1)$ & $16(2.5)$ & $1(2.1)$ & 0.554 \\
\hline Postoperative bleeding & $11(6.2)$ & $31(4.8)$ & $2(4.2)$ & 0.705 \\
\hline Aspiration pneumonia & $0(0)$ & $11(1.7)$ & $2(4.2)$ & 0.080 \\
\hline Stricture & $0(0)$ & $4(0.6)$ & $1(2.1)$ & 0.226 \\
\hline
\end{tabular}

parin bridging therapy, had longer hospitalization durations than that described in our clinical pathway (10 days before November 2013 and 7 days after December 2013). However, there were no significant differences in the average hospitalization times among the 3 groups $(P=0.209$, average hospitalization time: very elderly patients: 11.0 days [range 6 - 33]; elderly patients: 10.9 days [range $7-82$ ]; and non-elderly patients: 10.0 days [range $7-21])$. No procedure-related mortalities occurred during hospitalization, and all patients in the very elderly group were discharged in good condition.

\section{Long-term outcomes}

The median follow-up period after ESD was 48.0 months (range 2 -151). For the non-elderly, elderly, and very elderly groups, these values were 51.5, 48.0, and 35.0 months, respectively. There were no significant differences in the follow-up period 


\begin{tabular}{|c|c|c|c|c|c|c|c|c|c|}
\hline Case & Age & Gender & Location & $\begin{array}{l}\text { Reason for } \\
\text { non-curative } \\
\text { resection }\end{array}$ & Comorbidity & $\begin{array}{l}\text { Additional } \\
\text { treatment }\end{array}$ & $\begin{array}{l}\text { Follow-up } \\
\text { duration } \\
\text { (months) }\end{array}$ & Vital status & $\begin{array}{l}\text { Cause of } \\
\text { death in } \\
\text { fatal cases }\end{array}$ \\
\hline 1 & 86 & Male & $\mathrm{M}$ & $\begin{array}{l}\text { Sig, } 35 \mathrm{~mm} \text {, } \\
\mathrm{HM}+\end{array}$ & DM & Surgery & 107 & Dead & Pneumonia \\
\hline 2 & 85 & Male & $\mathrm{U}$ & $\mathrm{HM}+$ & Hypertension & Follow up & 90 & Alive & - \\
\hline 3 & 87 & Male & $\mathrm{U}$ & $\mathrm{HM}+$ & $\begin{array}{l}\text { OMI } \\
\text { Valvular heart } \\
\text { disease }\end{array}$ & Follow up & 2 & Untraceable & - \\
\hline 4 & 85 & Female & $\mathrm{L}$ & $\mathrm{SM} 1,52 \mathrm{~mm}$ & None & Follow up & 71 & Alive & - \\
\hline 5 & 85 & Female & $\mathrm{L}$ & Ly+ & Hypertension & Follow up & 46 & Alive & - \\
\hline 6 & 87 & Male & $\mathrm{U}$ & SM2, V+ & Hypertension & Follow up & 42 & Alive & - \\
\hline 7 & 85 & Male & $\mathrm{L}$ & $\mathrm{SM} 1,33 \mathrm{~mm}$ & None & Follow up & 40 & Alive & - \\
\hline 8 & 88 & Male & $\mathrm{L}$ & $\mathrm{SM} 2, \mathrm{~V}+$ & $\begin{array}{l}\text { Cardio- } \\
\text { myopathy } \\
\text { CHF }\end{array}$ & Follow up & 35 & Alive & - \\
\hline 9 & 87 & Female & $U$ & SM1, Ly + & $\begin{array}{l}\text { Hypertension } \\
\mathrm{Cl}\end{array}$ & Follow up & 30 & Alive & - \\
\hline 10 & 85 & Male & $\mathrm{U}$ & SM1, Ly + & Af, DM & Follow up & 29 & Alive & - \\
\hline 11 & 88 & Female & $M$ & SM2, Por & $\mathrm{Cl}$ & Follow up & 28 & Alive & - \\
\hline
\end{tabular}

among the 3 groups $(P=0.051)$. We performed follow-up on 152 patients $(94.4 \%)$ in the non-elderly group, 487 patients $(95.3 \%)$ in the elderly group, and 41 patients $(95.3 \%)$ in the very elderly group. Rates of follow-up endoscopic examinations for all patients and $\mathrm{CT}$ for patients with non-curative resections after ESD at least every 12 months were $75.2 \%$ in the non-elderly group, $69.7 \%$ in the elderly group, and $55.8 \%$ in the very elderly group. There were significant differences in overall survival among the 3 groups $(P=0.001$, $>$ Fig. 1 a). Overall survival rates in the very elderly group were lower than those in the elderly and non-elderly groups (1-, 5-, and 10 -year overall survival rates: very elderly patients: $92.7 \%, 66.8 \%$, and $34.4 \%$; elderly patients: $97.2 \%, 86.2 \%$, and $61.9 \%$; and non-elderly patients: $98.6 \%, 90.2 \%$, and $74.7 \%$, respectively).

Of the 11 non-curative patients in the very elderly group, only 1 underwent an additional surgery, and no residual lesions or lymph node metastases were observed in the resected specimens. The remaining 10 non-curative patients were followed up without additional treatment ( $\triangleright$ Table 4 ). In contrast, 30 of the non-curative patients $(37.0 \%)$ in the elderly group underwent additional surgery; residual cancers were detected in 5 cases, and lymph node metastases were observed in 3 cases. Seven of the non-curative patients (50.0\%) in the non-elderly group underwent additional surgery; residual cancers were detected in 2 cases, and no lymph node metastases were observed. Among all patients, only 1 non-elderly patient, who refused the additional surgery, died of recurrent gastric cancer 52 months after ESD. Other than this fatal case, no other recurrences were observed during the study period. The causes of death are summarized in $\downarrow$ Table 5 . A sudden death occurred in 1 very elderly case. This sudden death occurred at home 2 months after ESD, and the cause was not determined. That patient developed a stricture after ESD and endoscopic balloon dilatation was performed as an outpatient procedure.

In terms of comorbidity, the overall survival rate of very elderly patients with cardiovascular disease was significantly lower than that of the very elderly patients without cardiovascular disease $(P<0.001$, the $1-, 5-$, and 10 -year overall survival rates in very elderly patients with cardiovascular disease were $63.5 \%, 0 \%$, and $0 \%$, and values in very elderly patients without cardiovascular disease were $100 \%, 77.7 \%$, and $39.9 \%$, respectively, > Fig. 1b). In very elderly patients, differences in overall survival rates due to other comorbidities, use of antithrombotic agents, and gender were not significant.

\section{Discussion}

ESD is currently used for EGC with a negligible risk of lymph node metastasis and enables en bloc resection of tumors. However, ESD has some disadvantages, such as technical difficulty, a long procedure time, and frequency of AEs [2,3]. In very elderly patients who generally have low organ capacity [12], there is concern about the potential risk of AEs, such as perforation, intra-postoperative bleeding, aspiration pneumonia and AEs related to sedation. In the current study, rates of comorbid cardiovascular disease, hypertension, and cerebral vessel disease in the very elderly group were higher than those in the elderly and non-elderly groups. Moreover, the rate of antithrombotic agent use in the very elderly groups was higher than those in the elderly and non-elderly groups. However, rates of com- 

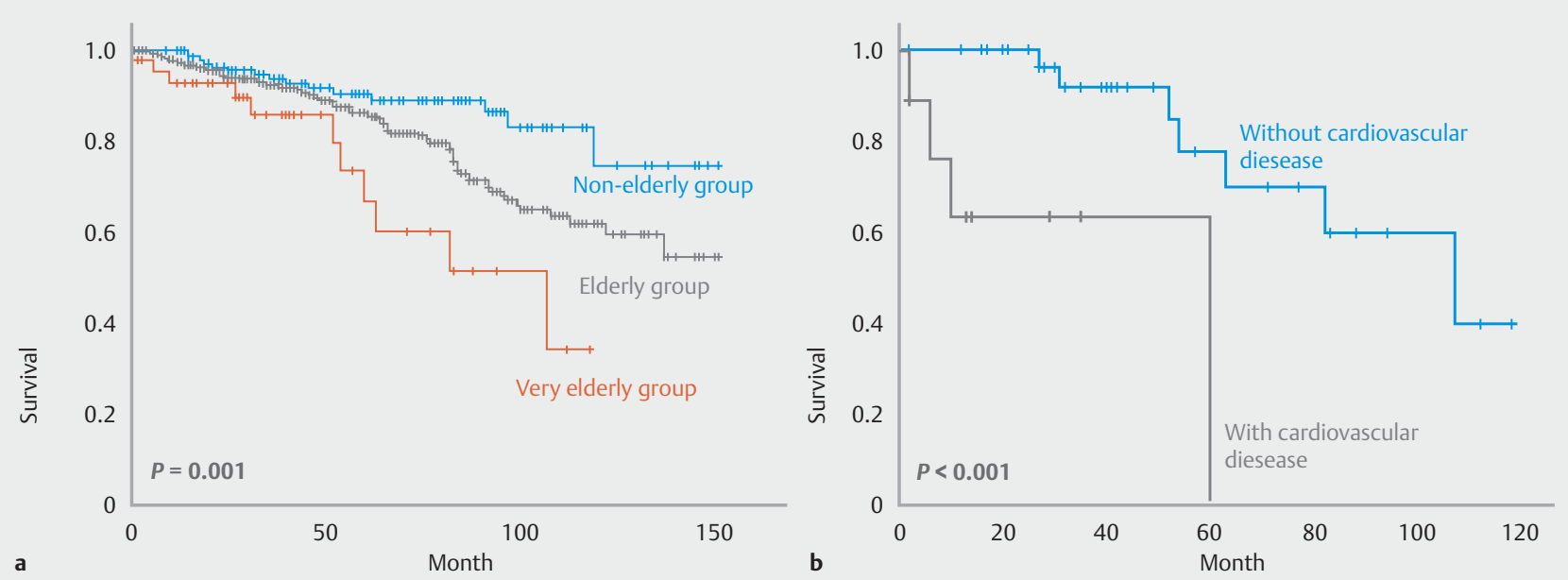

- Fig. 1a Overall survival rates in very elderly, elderly, and non-elderly patients following endoscopic submucosal dissection using the KaplanMeier method. There were significant differences in the overall survival rates between the 3 groups ( $P=0.001$, log-rank test). The 1-, 5-, and 10year overall survival rates in the very elderly group were $92.7 \%, 66.8 \%$, and $34.4 \%$, those in the elderly group were $97.2 \%, 86.2 \%$, and $61.9 \%$, and those in the non-elderly group were $98.6 \%, 90.2 \%$, and $74.7 \%$, respectively. b Overall survival rates in 2 groups of very elderly patients after endoscopic submucosal dissection (Kaplan-Meier method). The overall survival rate in patients with cardiovascular disease was significantly lower than that in those without cardiovascular disease $(P<0.001$, log-rank test).

Table 5 Causes of death.

\begin{tabular}{|c|c|c|c|}
\hline & $\begin{array}{l}\text { Non-elderly } \\
\text { ( } \leq 64 \text { years) }\end{array}$ & $\begin{array}{l}\text { Elderly } \\
\text { (65-84 years) }\end{array}$ & $\begin{array}{l}\text { Very elderly } \\
\text { ( } \geq 85 \text { years) }\end{array}$ \\
\hline Total deaths, $\mathrm{n}$ & 15 & 84 & 10 \\
\hline Cardiovascular disease, n (\%) & $1(6.7)$ & $12(14.3)$ & $2(20.0)$ \\
\hline Pneumonia, n (\%) & $1(6.7)$ & 10 (11.9) & $4(40.0)$ \\
\hline Other cancer, n (\%) & $5(33.3)$ & $28(33.3)$ & $2(20.0)$ \\
\hline Cerebral vessel disease, n (\%) & $0(0)$ & $7(8.3)$ & $0(0)$ \\
\hline Senile dementia, n (\%) & $0(0)$ & $11(13.1)$ & $1(10.0)$ \\
\hline Gastric cancer, n (\%) & $1(6.7)$ & $0(0)$ & $0(0)$ \\
\hline ESD-related death, $\mathrm{n}(\%)$ & $0(0)$ & $0(0)$ & $1(10)^{*}$ \\
\hline Others, n (\%) & $7(46.7)$ & $16(19.0)$ & $0(0)$ \\
\hline
\end{tabular}

plete en bloc resection and AEs following ESD for EGC in the very elderly group were comparable to those in the elderly and the non-elderly groups. There were significant differences in curative resection rates among the 3 groups; nevertheless no very elderly patients died of gastric cancer. In contrast, overall survival rates after ESD in the very elderly group were lower than those in the elderly and the non-elderly groups. Furthermore, the overall survival rate in the very elderly patients with cardiovascular disease was significantly lower than the rate in the very elderly patients without cardiovascular disease.

Several studies have reported that ESD for EGC in elderly patients (age $\geq 75$ or $\geq 80$ years) is effective [ $4-6,8-11]$. In addition, other studies have described ESD as effective and safe in patients with a comorbid disease $[15,16]$. In this study, the complete en bloc resection rate in the very elderly group was $93.6 \%$, which was comparable with rates in the elderly and non-elderly groups. In contrast, the curative resection rate in the very elderly group was $77.1 \%$, which was lower than rates in the other 2 groups. There were no significant differences in histologic types, depths of invasion, en bloc resection rates, complete en bloc resection rates, rate of horizontal margin-positive cases, rate of vertical margin-positive cases, rate of lymphatic invasion, or rate of vascular invasion among the 3 groups. Therefore, there seems to be no difference in indications for ESD based on endoscopic or mucosal biopsy finding among the 3 groups. Nevertheless, the curative resection rate 
in the very elderly group was lower than the rates in the other 2 groups due to the following cases: 1 case with a differentiated intramucosal cancer with lymphatic invasion, 2 cases with differentiated SM1 cancers of $3 \mathrm{~cm}$ or more, and 2 cases with differentiated SM 1 cancers of $3 \mathrm{~cm}$ or less with lymphatic invasion. Based on these results, multiple factors, which are difficult to diagnosis before ESD, were associated with the low curative resection rate in the very elderly group. However, further studies with large numbers of very elderly patients are necessary to confirm these findings.

In terms of $A E$, several researchers $[5,8,9,11]$ have reported that the rate of AEs associated with ESD is significantly higher in elderly patients $(\geq 75)$. Therefore, based on these reports, more careful management for ESD is required to prevent AEs in elderly patients; for example, ESD in elderly patients should be performed by expert physicians, and the oral cavity should be frequently cleared with suction to remove any saliva and prevent aspiration pneumonia [11]. In this study, there were no significant differences in rates of AEs among the very elderly, elderly, and non-elderly groups. However, in 1 case of stricture that required endoscopic balloon dilatation in the very elderly group, the patient died suddenly at home 2 months after ESD. The cause of death was unknown; however, the possibility that dehydration due to poor oral ingestion was responsible cannot be excluded. This case should thus be classified as an ESD-related death. Severe AEs in patients with low organ capacity may be fatal. Therefore, such cases need to be managed more carefully. For example, an intravenous drip should be administered to prevent dehydration, and an endoscopic balloon dilatation for stricture after ESD should be performed in the hospital.

The natural history of EGC has been poorly clarified. Therefore, whether EGC affects the prognoses of very elderly patients, regardless of presence or absence of ESD, has not been clarified. Tsukuma et al. [17] reported that EGC displays a relatively long natural history in general and estimated that the median duration of those who remain in the early stage is 44 months. Fujisaki et al. [18] reported a case of gastric cancer that was followed up for 8 years. In that case, endoscopic findings demonstrated that the tumor exhibited the morphology of an EGC for approximately 5 years and then developed into advanced cancer. These reports suggest that EGCs are probably not the ultimate cause of death and that patients will experience a decline in their quality of life over several years without ESD or other treatments. In our study, the overall survival rate in the very elderly group was lower than the rates in the elderly and non-elderly groups. In addition, the overall survival rate in the very elderly patients with cardiovascular disease was significantly lower than the rate in very elderly patients without cardiovascular disease. Yoshifuku et al. [13] also reported that very elderly patients with comorbidities are at a high risk of poor prognoses after ESD for EGC. Based on these results, ESD for EGC in very elderly patients with expected long-term survival may prevent them from dying of gastric cancer; however, ESD may not help prolong survival in very elderly patients without expected long-term survival due to other diseases, particularly cardiovascular disease. Because the rate of AEs in very elderly patients was not higher than that of the other patients in this study, if a patient consents to undergoing ESD after he or she understands that a severe AE may be fatal, ESD is acceptable for very elderly patients who are eligible for ESD or emergency surgery. In contrast, we have occasionally encountered very elderly patients who do not wish to undergo ESD. In such cases, particularly those with cardiovascular disease, follow-up without ESD may be an option based on the long-term outcomes observed here and the natural history of EGC that has been reported in previous literature $[17,18]$.

In general, gastrectomy with lymph node dissection is the gold standard curative treatment for EGCs with risk of lymph node metastases, such as deep submucosal invasion and lymphovascular invasion [19]. Kusano et al. [20] reported that additional surgery following non-curative endoscopic resection improves overall and disease-free survival rates compared with non-surgical observation but only in patients older than age 75. Kiyokawa et al. [21] reported that gastrectomy with standard lymph node dissection for gastric cancer may be acceptable for relatively healthy patients over 85 . In our study, 10 noncurative cases among very elderly patients were followed up without additional treatment, and no recurrence was observed in any patient during the study period. Of the 10 non-curative cases who did not receive additional treatment, only 1 patient was deemed a poor candidate for additional surgery due to severe chronic heart failure. Therefore, we recommended that the other 9 patients undergo additional surgery because they were at risk for lymph node metastasis. However, they did not want to undergo the surgery because CTs done at the time did not indicate lymph node metastasis, and they were anxious about possible decline in their physical conditions due to stomach resection. In contrast, only 1 patient who underwent additional surgery was alive 107 months after ESD. It remains unclear whether very elderly patients with non-curative resection and a risk of lymph node metastasis should undergo the additional surgery. Additional studies are necessary to address this question.

This study has several limitations. First, it was retrospective and conducted at a single institution. The second limitation is the small number of very elderly patients studied. Third, ESD was not performed for very elderly patients with PSs of 2 or greater or those with severe comorbidities. Thus, there was a selection bias for patients with regard to safety of ESD. Finally, we did not compare survival rates in very elderly patients with EGC between those who underwent ESD and those who did not. Further prospective studies are necessary to confirm the safety and efficacy of ESD for EGD in very elderly patients.

\section{Conclusion}

In conclusion, the safety of ESD for EGC is acceptable in very elderly patients who are eligible for ESD and do not have severe comorbidities. Overall survival after ESD in the very elderly patients with cardiovascular disease was short. If very elderly patients, especially those with cardiovascular disease, do not agree to undergo ESD, follow-up without ESD may be an option. 


\section{Acknowledgements}

We express our gratitude to all of the endoscopy medical staff at Fukushima Medical University Hospital for their collaboration and assistance with endoscopic procedures.

\section{Competing interests}

None

\section{References}

[1] Suzman R. Willis DP. Manton KG. Introducing the oldest old. In: Suzman R. Willis DP. Manton KG , eds. The oldest old. New York: Oxford University Press; 1992

[2] Oda I. Saito D. Tada M et al. A multicenter retrospective study of endoscopic resection for early gastric cancer. Gastric Cancer 2006; 9 : $262-270$

[3] Isomoto H. Shikuwa S. Yamaguchi N et al. Endoscopic submucosal dissection for early gastric cancer: a large-scale feasibility study. Gut 2009; 58: $331-336$

[4] Kakushima N. Fujishiro M. Kodashima S et al. Technical feasibility of endoscopic submucosal dissection for gastric neoplasms in the elderly Japanese population. J Gastroenterol Hepatol 2007; 22: 311 314

[5] Isomoto H. Ohnita K. Yamaguchi $\mathrm{N}$ et al. Clinical outcomes of endoscopic submucosal dissection in elderly patients with early gastric cancer. Eur J Gastroenterol Hepatol 2010; 22: 311-317

[6] Abe N. Gotoda T. Hirasawa T et al. Multicenter study of the long-term outcomes of endoscopic submucosal dissection for early gastric cancer in patients 80 years of age or older. Gastric Cancer 2012; 15: 70 75

[7] Tokioka S. Umegaki E. Murano M et al. Utility and problems of endoscopic submucosal dissection for early gastric cancer in elderly patients. J Gastroenterol Hepatol 2012; 27: 63-69

[8] Toyokawa T. Fujita I. Morikawa T et al. Clinical outcomes of ESD for early gastric neoplasms in elderly patients. Eur J Clin Invest 2011; 41: $474-478$
[9] Zhang Y. Huang L. Li L et al. Endoscopic submucosal dissection for early gastric neoplasms in elderly patients. J Laparoendosc Adv Surg Tech A 2014; 24: 391 - 398

[10] Chinda D. Sasaki Y. Tatsuta T et al. Perioperative adverse events of endoscopic submucosal dissection for early gastric cancer in elderly Japanese patients 75 years of age or older. Intern Med 2015; 54: 267 272

[11] Kato M. Michida T. Kusakabe A et al. Safety and short-term outcomes of endoscopic submucosal dissection for early gastric cancer in elderly patients. Endosc Int Open 2016; 4: E521 - E526

[12] Arai T. Esaki Y. Inoshita $\mathrm{N}$ et al. Pathologic characteristics of gastric cancer in the elderly: a retrospective study of 994 surgical patients. Gastric Cancer 2004; 7: 154-159

[13] Yoshifuku Y. Oka S. Tanaka S et al. Long-term prognosis after endoscopic submucosal dissection for early gastric cancer in super-elderly patients. Surg Endosc 2016; 30: 4321 - 4329

[14] Japanese Gastric Cancer Association. Japanese classification of gastric carcinoma: 3rd English edition. Gastric Cancer 2011; 14: 101 - 112

[15] Man-i M. Morita Y. Fujita T et al. Endoscopic submucosal dissection for gastric neoplasm in patients with co-morbidities categorized according to the ASA physical status classification. Gastric Cancer 2013; 16 : $56-66$

[16] Kim BJ. Chang TH. Kim JJ et al. Efficacy and safety of endoscopic submucosal dissection for early gastric cancer in patients with comorbid diseases. Gut Liver 2010; 4: 186-191

[17] Tsukuma H. Oshima A. Narahara H et al. Natural history of early gastric cancer: a non-concurrent, long term, follow up study. Gut 2000; 47: $618-621$

[18] Fujisaki J. Nakajima T. Hirasawa T et al. Natural history of gastric cancer-a case followed up for eight years: early to advanced gastric cancer. Clin J Gastroenterol 2012; 5: 351 - 354

[19] Gotoda T. Yanagisawa A. Sasako M et al. Incidence of lymph node metastasis from early gastric cancer: estimation with a large number of cases at two large centers. Gastric Cancer 2000; 3: 219-225

[20] Kusano C. Iwasaki M. Kaltenbach T et al. Should elderly patients undergo additional surgery after non-curative endoscopic resection for early gastric cancer? Long-term comparative outcomes Am J Gastroenterol 2011; 106: $1064-1069$

[21] Kiyokawa T. Hiki N. Nunobe S et al. Feasibility of gastrectomy with standard lymphadenectomy for patients over 85 years old with gastric cancer. Ann Surg Oncol 2015; 22: 3962 - 3969 